Vol. 22, No. 2, Oktober 2020

\title{
MODEL SISTEM BASIS DATA UNTUK PERENCANAAN ALOKASI AIR
}

\author{
Edy Sriyono $^{1}$, Nindyo Cahyo Kresnanto ${ }^{1}$, Adi Sutarto ${ }^{1}$ \\ ${ }^{I}$ Magister Teknik Sipil, Universitas Janabadra, Yogyakarta 55231 \\ E-mail :edysriyono@janabadra.ac.id \\ E-mail : nindyo_ck@janabadra.ac.id \\ E-mail :adisutarto@yahoo.com
}

\begin{abstract}
ABSTRAK
Dalam melakukan perencanaan alokasi air secara komprehensif, terpadu dan berkelanjutan, diperlukan model basis data yang lengkap, sesuai, dan praktis sehingga dapat diaplikasikan dengan optimal. Model sistem basis data dalam penelitian terdiri atas beberapa tabel yang dihubungkan dalam sebuah Entity Relationship (ER) Diagram. Tabel yang menjadi pusat dari proses running adalah tabel neraca_district (daerah layanan air). Tabel tersebut mendapat input dari tabel supply, demand, potensi dan water district. Perhitungan alokasi air harus memperhatikan aspek ruang, waktu, kuantitas, dan kualitas. Normalisasi data dan menyusunnya dalam tabel-tabel tersendiri agar tidak terjadi duplikasi data merupakan tahapan yang penting dalam penyusunan sebuah model basis data. Model sistem basis data alokasi air sangat tergantung dari ER Diagram, karena hubungan tabel satu dengan tabel lainnya akan berpengaruh terhadap berjalannya sistem. Model sistem basis data yang digunakan adalah parent-child structure, karena mampu membangun sistem alokasi secara berantai, maksudnya hasil satu water district dapat menjadi input bagi water district di bagian hilirnya. Penelitian ini sudah bisa membangun sebuah model sistem basis data spasial untuk perencanaan alokasi air dengan mempertimbangkan aspek ruang dan waktu. Sehingga kondisi alokasi air hasil analisis dapat dilihat secara langsung karena system basis data diolah dengan cara membangun hubungan antar entitas yang ada dalam sistem.
\end{abstract}

Kata Kunci: sistem basis data, alokasi air, parent-child structure

\section{ABSTRACT}

In carrying out water allocation planning in a comprehensive, integrated, and sustainable manner, a complete, appropriate and practical database model is needed so that it can be optimally applied. The database system model in this study consists of several tables that are linked in an Entity Relationship (ER)Diagram. The table that is the center of the running process is the neraca_district table (water service area). The table gets input from the supply, demand, potential and water district tables. Calculation of water allocation must pay attention to aspects of space, time, quantity, and quality. Normalizing data and arranging it in separate tables so that data duplication does not occur is an important stage in compiling a database model. The water allocation database system model is highly dependent on the ER Diagram because the relationship between one table and another will affect the operation of the system. The database system model used is the parent-child structure because it is able to build a chain allocation system, meaning that the results of one water district can be an input for the water district downstream. This research has been able to build a model spatial database system for planning water allocation by considering the aspects of space and time. So that the condition of water allocation results of the analysis can be seen directly because the database system is processed by building relationships between entities in the system.

Keywords: database system, water allocation, parent-child structure

\section{PENDAHULUAN}

Saat ini sudah banyak cara menganalisis alokasi air dalam rangka perencanaan pengelolaan sumber daya air. Namun diantaranya masih belum mempertimbangkan lokasi sumber air dan daerah layanan atau cakupan analisisnya masih bersifat lokal atau skala kecil. Sedangkan kalau daerah perencanaannya meliputi seluruh wilayah sungai, akan mencakup daerah yang cukup luas. Untuk itu maka diperlukan sebuah model perencanaan pengelolaan sumber daya air terutama dalam analisis neraca air dalam rangka untuk alokasi air yang mampu menganalisis untuk skala yang luas dan sudah mempertimbangkan lokasi unsur-unsur yang menjadi obyek perhitungan [1]. 
Namun sebelum itu diperlukan sebuah sistem data yang akan menjelaskan skema hubungan antara berbagai jenis data yang akan digunakan dalam analisis serta tahapan-tahapan yang harus dilakukan [2][3].

Saat ini model perhitungan alokasi air berbasis lokasi telah banyak dikembangkan namun dengan studi kasus lokasi di luar Indonesia [4][5][6], sehingga perlu melakukan penelitian terkait hal ini dengan studi kasus di Indonesia. Penelitian dilakukan dengan membuat sebuah sistem basis data spasial yang komprehensif dan terpadu sesuai dengan prinsip pengelolaan sumber daya air di mana analisis neraca air tidak dilakukan secara terpisah-pisah, namun akan dilakukan secara serentak dalam sebuah skenario. Penelitian ini bertujuan membuat sebuah sistem basis data yang optimal digunakan dalam perencanaan alokasi air di suatu wilayah sungai (satu sistem perencanaan).

\section{TINJAUAN PUSTAKA}

\subsection{Alokasi Air}

Alokasi air merupakan cara membagi air kepada para pengguna air dengan cara menyediakan air dalam jumlah tertentu di suatu daerah pelayanan (water district) tertentu sehingga dapat terdistribusi secara adil, merata, dan efisien [1]. Alokasi air dapat dilayani melalui bangunan-bangunan air seperti bangunan utama atau bangunan pengambilan, saluran induk/sekunder, dan beberapa bangunan air lainnya.

Dengan mempelajari studi terdahulu dan melakukan survei dan inventarisasi sistem alokasi air yang ada di lapangan dapat diketahui konsep sistem alokasi air yang ada di daerah layanan tersebut. Jika ternyata terdapat ketidak optimalan dalam penerapan alokasi air (misal dalam menetapkan sistem golongan pada suatu daerah irigasi), berikut ini disampaikan beberapa petunjuk yang dapat digunakan sebagai acuan.

Penetapan alokasi air kepada para pengguna air untuk berbagai kebutuhan air sangat tergantung dari ketersediaan air yang ada di daerah layanan tersebut dan dapat dilakukan dengan teknik optimasi [7]. Adapun skala prioritas penetapan alokasi air dilakukan dengan urutan sebagai berikut:

1) Jika air yang tersedia lebih besar daripada air yang dibutuhkan maka semua pengguna air akan mendapatkan air sesuai dengan kebutuhan air masing-masing pengguna.

2) Jika air yang tersedia lebih kecil daripada air yang dibutuhkan maka alokasi air ditentukan berdasarkan teknik optimasi dengan mempertimbangkan keadilan, pemerataan, manfaat, prioritas, nilai ekonomi, dan aspek lain yang dikualifikasi dalam fungsi tujuan dan kendala, untuk mendapatkan solusi optimalnya.

Berikut ini disampaikan konsep perencanaan river basin alokasi air sebagaimana terlihat pada Gambar 1.

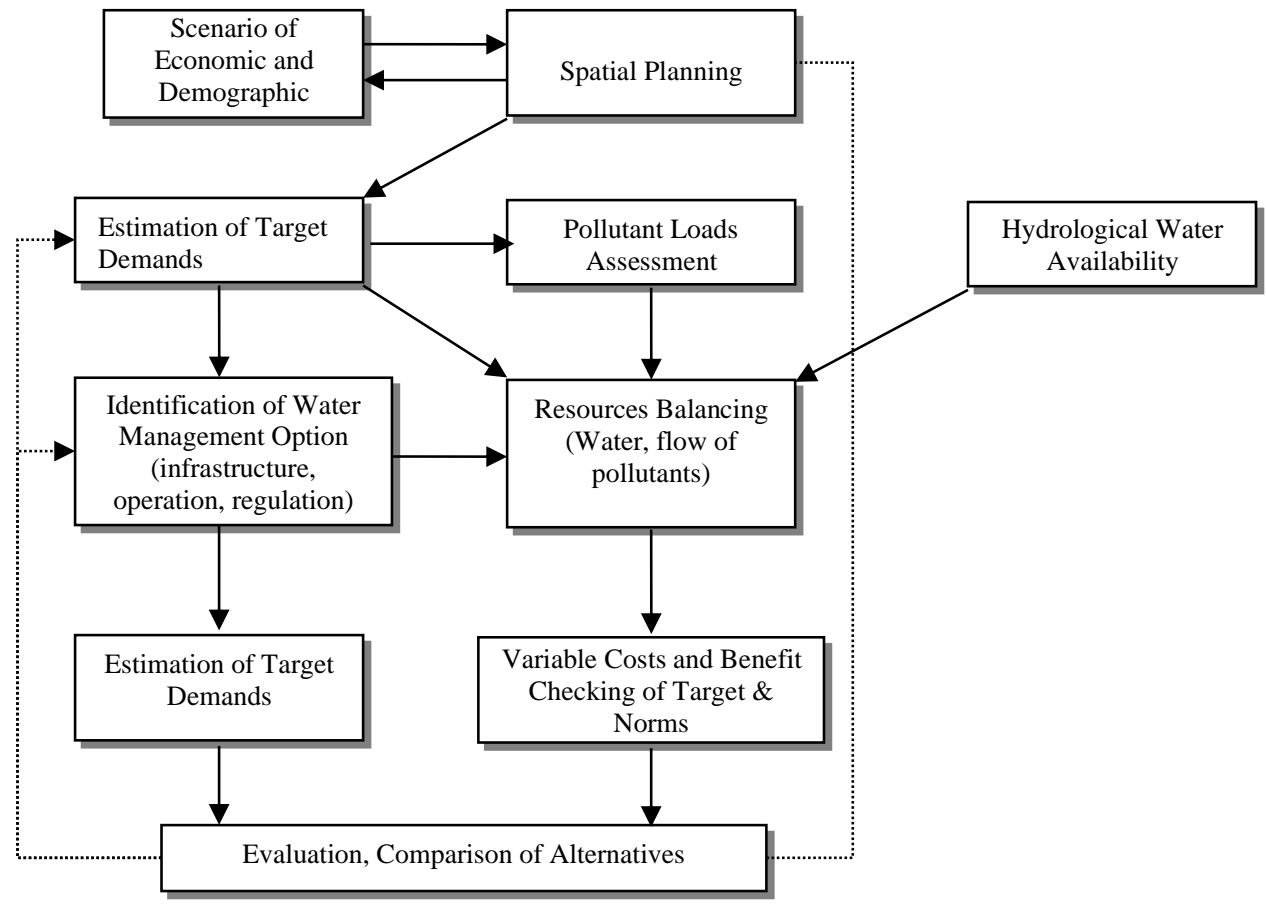

Gambar 1. Konsep Perencanaan River Basin/Alokasi Air 


\subsection{Sistem Basis Data}

Sistem Basis Data (SBD) merupakan sekumpulan basis data dengan para pemakai yang menggunakan basis data secara bersamasama, personil yang merancang dan mengelola basis data, teknik-teknik untuk merancang dan mengelola basis data, serta sistem komputer yang mendukungnya [2]. Komponen-komponen utama penyusun sistem basis data adalah: Perangkat keras, Sistem operasi, Basis data, Sistem pengelola basis data (DBMS), dan Pemakai (Programmer, User mahir, user umum, user khusus) Sistem basis data biasanya menyembunyikan detail tentang bagaimana data disimpan dan dipelihara. Oleh karena itu, sering kali data yang terlihat oleh pemakai sebenarnya berbeda dengan yang tersimpan secara fisik. Abstraksi data merupakan level bagaimana melihat data dalam sebuah sistem basis data.

Model Entity Relationship diperkenalkan pertama kali oleh P.P. Chen pada tahun 1976. Model ini dirancang untuk menggambarkan persepsi dari pemakai dan berisi obyek-obyek dasar yang disebut entity dan hubungan antar entity-entity tersebut yang disebut relationship. Pada model ER ini semesta data yang ada dalam dunia nyata ditransformasikan dengan memanfaatkan perangkat konseptual menjadi sebuah diagram, yaitu diagram ER (Entity Relationship). Diagram Entity-Relationship melengkapi penggambaran grafik dari struktur logika. Dengan kata lain Diagram E-R menggambarkan arti dari aspek data seperti bagaimana entity-entity, atribut-atribut dan relationship-relationship disajikan. Sebelum membuat Diagram E-R, tentunya kita harus memahami betul data yang diperlukan dan ruang lingkupnya. Di dalam pembuatan diagram E-R perlu diperhatikan penentuan sesuatu konsep apakah merupakan suatu entity, atribut atau relationship [8].

\subsection{Sistem Informasi Geografis}

Sistem Informasi Geografis (SIG) dapat didefinisikan sebagai kumpulan yang terorganisir dari perangkat keras komputer, perangkat lunak (software), data geografis dan personil yang didesain untuk memperoleh, menyimpan, memperbaiki, menganalisa dan menampilkan semua bentuk informasi yang mempunyai referensi geografis (spasial) [9]. Keuntungan menggunakan SIG meliputi: Memberikan informasi yang lebih baik, Mempunyai kemampuan analisis kualitas tinggi, Kemampuan untuk melaksanakan skenario "bagaimana jika?/what if?"،, dan Meningkatkan efisiensi pekerjaan/proyek.

Hubungan data dalam SIG dibagi dua, yaitu: (1) Exact Matching dan (2) Non-Exact Matching. Non-Exact Matching dibagi lagi menjadi dua, yaitu: (1) Hierarchical Matching dan (2) Fuzzy Matching [6]. Topology adalah pendefinisian secara matematis yang menerangkan hubungan relative antara objek yang satu dengan objek yang lain (membangun hubungan spasial antar obyek). Dalam SIG topology didefinisikan oleh user sesuai dengan karakteristik data seperti line, polygon maupun point/titik. Setiap karakteristik data tertentu mempunyai rule/aturan tertentu. Rule atau aturan tersebut secara default telah disediakan oleh software GIS [10].

\subsection{Model Alokasi Air RIBASIM}

Software RIBASIM (River Basim Simulation) merupakan perangkat lunak optimasi alokasi air buatan DELFT University yang saat ini merupakan software standar Direktorat Jenderal SDA. Perangkat tersebut dapat digunakan untuk menyimulasi permasalahan yang berhubungan dengan imbangan/alokasi air pada suatu daerah aliran sungai atau beberapa aliran sungai yang cukup kompleks dengan berbagai pengguna air seperti air irigasi, tenaga air, air minum, dan industri serta pengendalian banjir [7].

RIBASIM dapat dimanfaatkan untuk tujuan perencanaan pengelolaan sistem sumber daya air jangka menengah atau jangka panjang terutama yang mempunyai konflik kebutuhan air, selain itu juga dapat digunakan untuk menyimulasi permasalahan yang berhubungan dengan imbangan air pada suatu aliran sungai dan mengevaluasi alternatif-alternatif pengembangan pengelolaan sumber dan pemanfaatan air pada daerah aliran sungai tersebut. Software RIBASIM juga punya kemampuan untuk menyimulasikan potensi sumber daya air, baik yang berasal dari air permukaan maupun air tanah. Output dari RIBASIM dapat berupa sistem alokasi air, kekurangan-kekurangan yang ada pada daerah pelayanan, dll.

\section{METODE PENELITIAN}

Dalam perencanaan pengelolaan alokasi air, peta menjadi unsur yang sangat penting dan harus disiapkan di awal kegiatan. Peta berguna untuk menunjukkan lokasi baik sebuah wilayah maupun prasarana yang akan dianalisis. Di samping itu peta juga akan digunakan untuk membuat skema jaringan alokasi air agar sesuai dengan gambaran di lapangan. Pembuatan skema jaringan untuk analisis alokasi air berbasis pada SIG dengan membuat topologi pada unsur-unsur geografisnya (line, node, polygon). Proses topologi data spasial merupakan proses normalisasi data yang berientasi lokasi (data dengan referensi geografis tertentu).

Setelah peta dan skema jaringan siap, maka tahap berikutnya adalah menyiapkan data input. Data input dibagi menjadi 2 yaitu: data dasar dan data hasil analisis. Seluruh data tersebut di-input-kan ke dalam skema jaringan yang telah dibuat sebelumnya sesuai dengan kondisi kasus (case) nya. Setelah itu harus dimasukkan prioritasi penggunaan airnya antara berbagai pengguna air sesuai dengan kriteria yang sudah ada. 
Setelah itu model akan di-running setiap kasus secara berurutan. Dalam sebuah kegiatan bisa terdiri atas beberapa kasus sesuai dengan kebutuhannya. Setelah itu hasil running dari model tersebut akan dianalisis untuk menentukan rencana alokasi yang akan digunakan baik untuk skenario saat ini maupun di masa yang akan datang sesuai dengan rencana periode waktu yang ditentukan. Gambaran mengenai alur pikir penelitian disajikan pada Gambar 2.

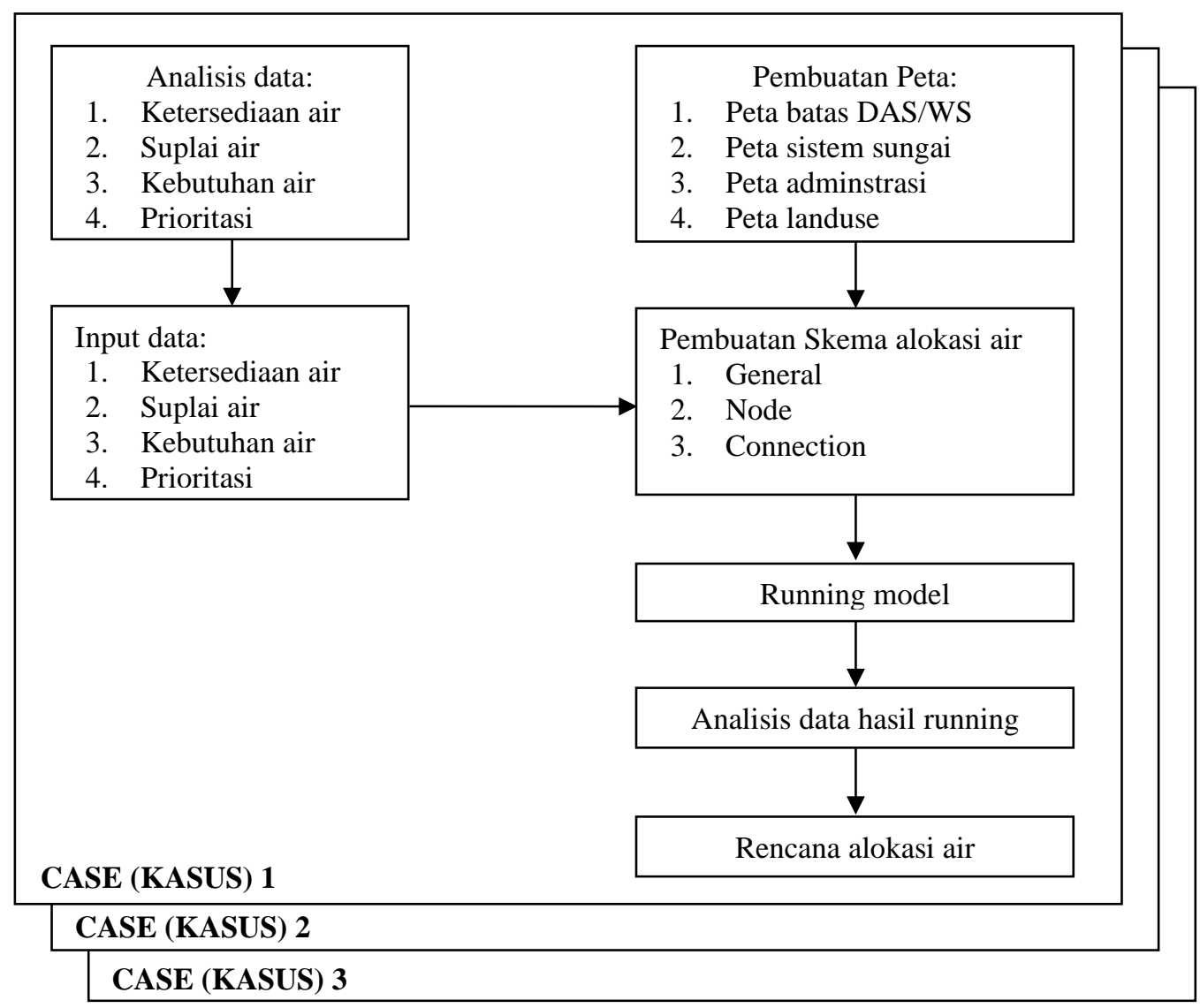

Gambar 2. Alur pikir penelitian

Penelitian ini akan mengkaji dan menyusun sistem data untuk perencanaan alokasi air di suatu wilayah sungai dan membandingkannya dengan model yang sudah ada. Sebagai bahan komparasi dalam penelitian ini digunakan Software River Basin Simulation Model (Ribasim).

\section{HASIL DAN PEMBAHASAN}

\subsection{Konsep Alokasi Air}

Berdasarkan perhitungan analisis imbangan air dalam sebuah sistem jaringan maka secara langsung dapat dilihat kondisi alokasi airnya. Oleh karena itu proses penyusunan skema jaringan alokasi air menjadi sangat penting karena akan sangat menentukan seluruh hasil analisis. Gambar 3 adalah contoh skema jaringan alokasi air di suatu Daerah Layanan Air. 


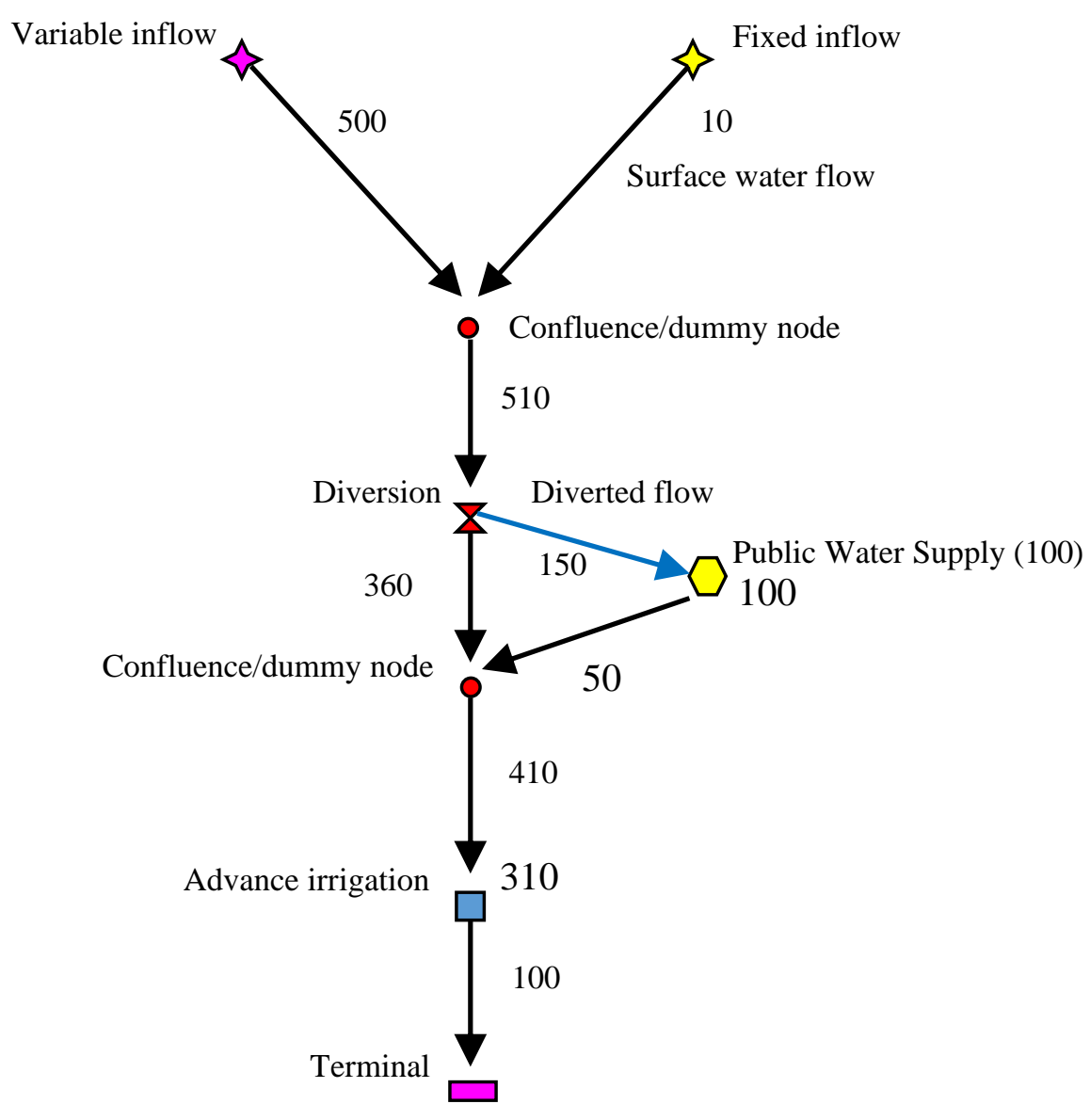

Gambar 3. Contoh skema jaringan alokasi air

\subsection{Sistem Data Alokasi Air}

Sistem basis data alokasi air disusun dengan menggunakan software MySQL. Aplikasi ini menyediakan fasilitas untuk mengolah basis data dengan membangun hubungan antar entitas yang ada dalam sistem.

Langkah-langkah yang dilakukan untuk menyusun basis data alokasi air adalah:

1) Membuat tabel-tabel yang diperlukan untuk input basis data.

2) Membuat Entity Relationship Diagram (ER Diagram)/diagram hubungan antar entitas.

3) Membuat query untuk menampilkan atau memilih keluaran sesuai dengan kebutuhan.

4) Membuat aplikasi untuk tampilan agar mudah diakses oleh pengguna.

Penjelasan masing-masing langkah tersebut di atas adalah sebagai berikut.

\subsubsection{Membuat Tabel}

Tabel yang akan dibuat dalam penelitian ini berjumlah 9 (sembilan) buah tabel. Pembuatan tabel-tabel ini bertujuan agar tidak terjadi duplikasi dalam baris (record) nya. Tabel-tabel tersebut adalah:

1) Tabel waterdistrict. Tabel ini berisi daftar waterdistrict atau daerah pelayanan air atau sub DAS sebagai satuan terkecil dalam pengelolaan dan alokasi air.

2) Tabel datapotensi. Tabel ini berisi daftar record atau input data potensi debit per satuan waktu per water district.

3) Tabel supply. Tabel ini berisi daftar suplai air yang diambil dari suatu infrastruktur bangunan air seperti pompa, bendung, freeintake dan lain-lain, per water district atau daerah pelayanan air.

4) Tabel datasupply. Tabel ini berisi data record suplai air per waterdistrict atau daerah pelayanan air atau sub DAS. Input data per water district bisa lebih dari satu data.

5) Tabel jenisdemand. Tabel jenis demand ini berisi jenis kebutuhan air dimana dalam model ini sebagai contoh akan dibagi menjadi dua yaitu kebutuhan air domestik dan industri. 
6) Tabel demand. Tabel ini berisi daftar kebutuhan air di masing-masing water district atau daerah pelayanan air atau sub DAS.

7) Tabel data demand. Tabel ini berisi data record kebutuhan air termasuk jenis dan debitnya per water district atau daerah pelayanan air atau sub DAS.

8) Tabel neracadistrict. Tabel neraca district merupakan tempat atau wadah untuk perhitungan analisis imbangan air.

9) Tabel neracawaterdistrict. Tabel ini adalah tabel yang menghubungkan antara satu water district dengan water district yang lain ketika dilakukan analisis perhitungan neraca air.

\subsubsection{Membuat Entity Relationship Diagram (ER Diagram)}

ER Diagram dibuat untuk membuat hubungan antara satu entitas dengan entitas yang lain. Satu record data dalam sebuat tabel/entitas dapat berhubungan dengan satu atau banyak ditabel yang lain. Jika satu record tabel selalu berhubungan dengan satu record tabel di tabel yang lain maka hubungan tersebut di sebut $1: 1$ (one to one). Namun jika satu record data berhubungan dan banyak record data dari tabel lain maka hubungan tersebut disebut $1: n$ (one to many). Atau terkadang ada banyak record data dalam sebuah tabel berhubungan dengan banyak record data di tabel yang lain dan disebut $n: m$ (many to many).

Sebagai contoh setiap record pada tabel waterdistrict akan dibaca oleh satu record data di tabel neracadistrict. Oleh karena itu hubungan ini disebut $1: 1$ (one to one). Contoh yang lain misalnya satu id demand di tabel demand memiliki banyak record/data di tabel data demand oleh karena itu hubungannya yang terjadi adalah $1: n$ (one to many), dimana satu record data pada tabel demand berhubungan dengan banyak data di tabel datademand.

Dalam penelitian ini seluruh hubungannya adalah one to many kecuali hubungan tabel waterdistrict dengan neracadistrict. Gambar ER Diagram untuk perencanaan alokasi air yang disusun dalam penelitian ini disajikan pada Error! Reference source not found. 4 .

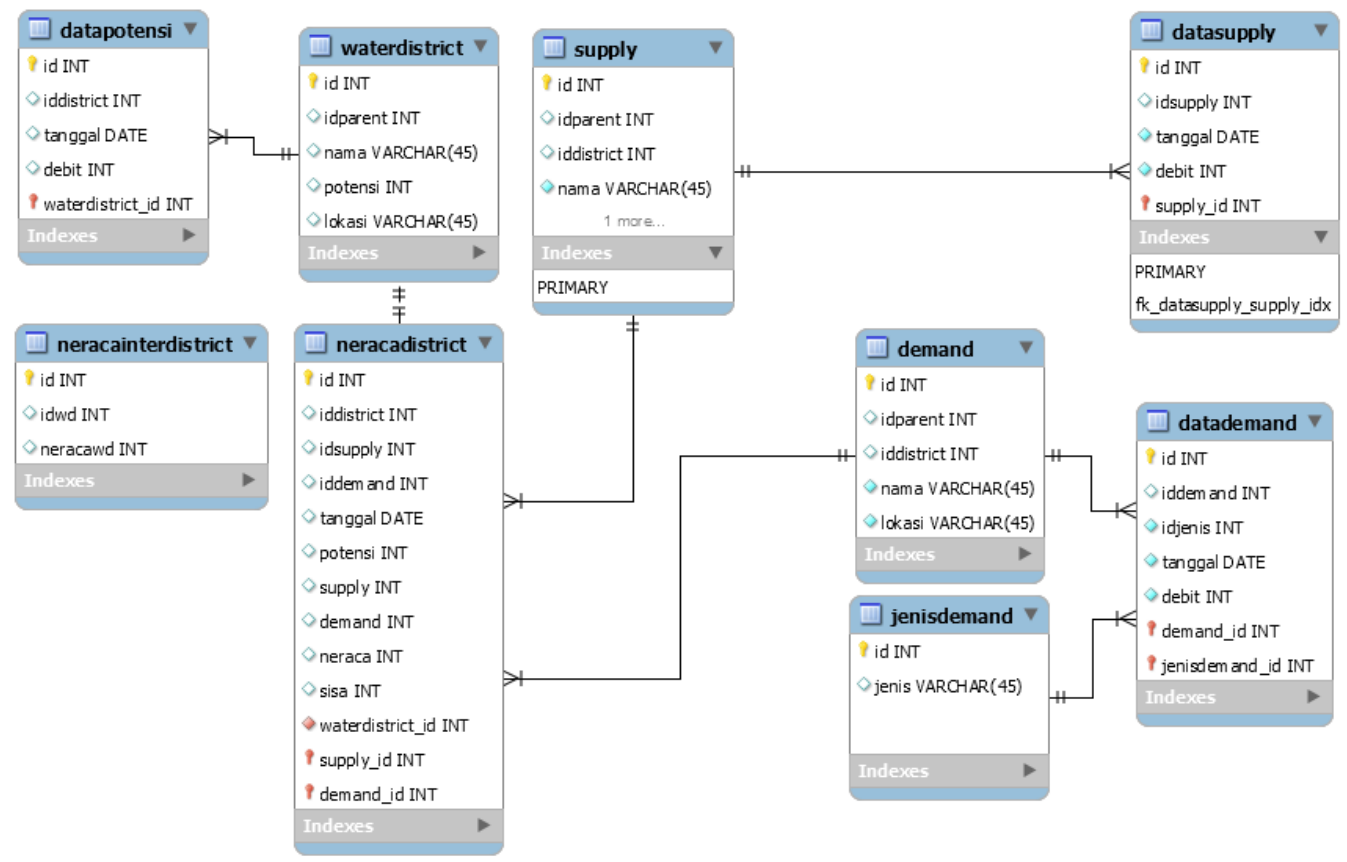

Gambar 4. ER Diagram alokasi air

\subsubsection{Input Data}

Tahap berikutnya adalah melakukan input data pada setiap data dengan memperhatikan id nya agar hubungan antar tabel dapat terjalin dengan baik sesuai dengan tujuan pembuatannya. Sebagai contoh adalah input data pada tabel data supply. Kolom pertama adalah id, kolom ini secara otomatis akan terisi secara berurutan mulai dari angka 1. Kolom kedua adalah id supply, diisi sesuai dengan kode pada tabel supply. Gambar input data pada tabel supply dan tabel data supply disajikan pada Error! Reference source not found. 5 . 


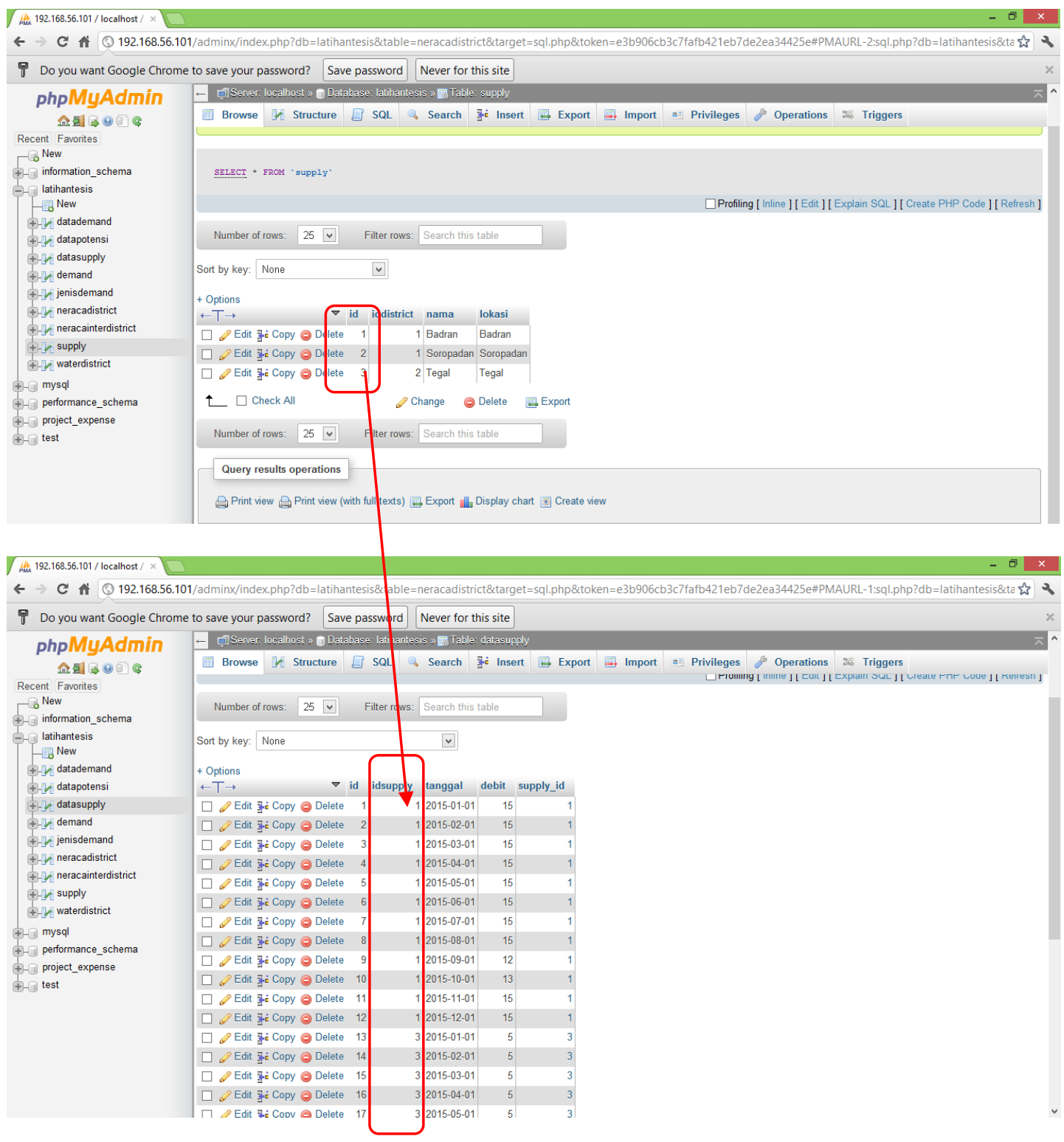

Gambar 5. Form input tabel supply dan tabel data supply

\subsubsection{Membuat Query}

Setelah hubungan antar entitas sudah dibuat dan tidak ada kegagalan dalam menentukan hubungan maka tahap berikutnya adalah membuat query. Query merupakan sekumpulan perintah yang merupakan tahapan untuk menghitung neraca air. Perintah query tersebut harus dilakukan dengan berurutan karena satu hasil perhitungan dari sebuah perintah akan dipakai untuk input perintah berikutnya. Urutan perintah dalam query untuk penelitian ini disajikan pada Error! Reference source not found.6.

Query dibuat dengan menempatkan kursor pada tabel neraca district dan hasilnya dapat dilihat seperti disajikan pada Error! Reference source not found.7. 


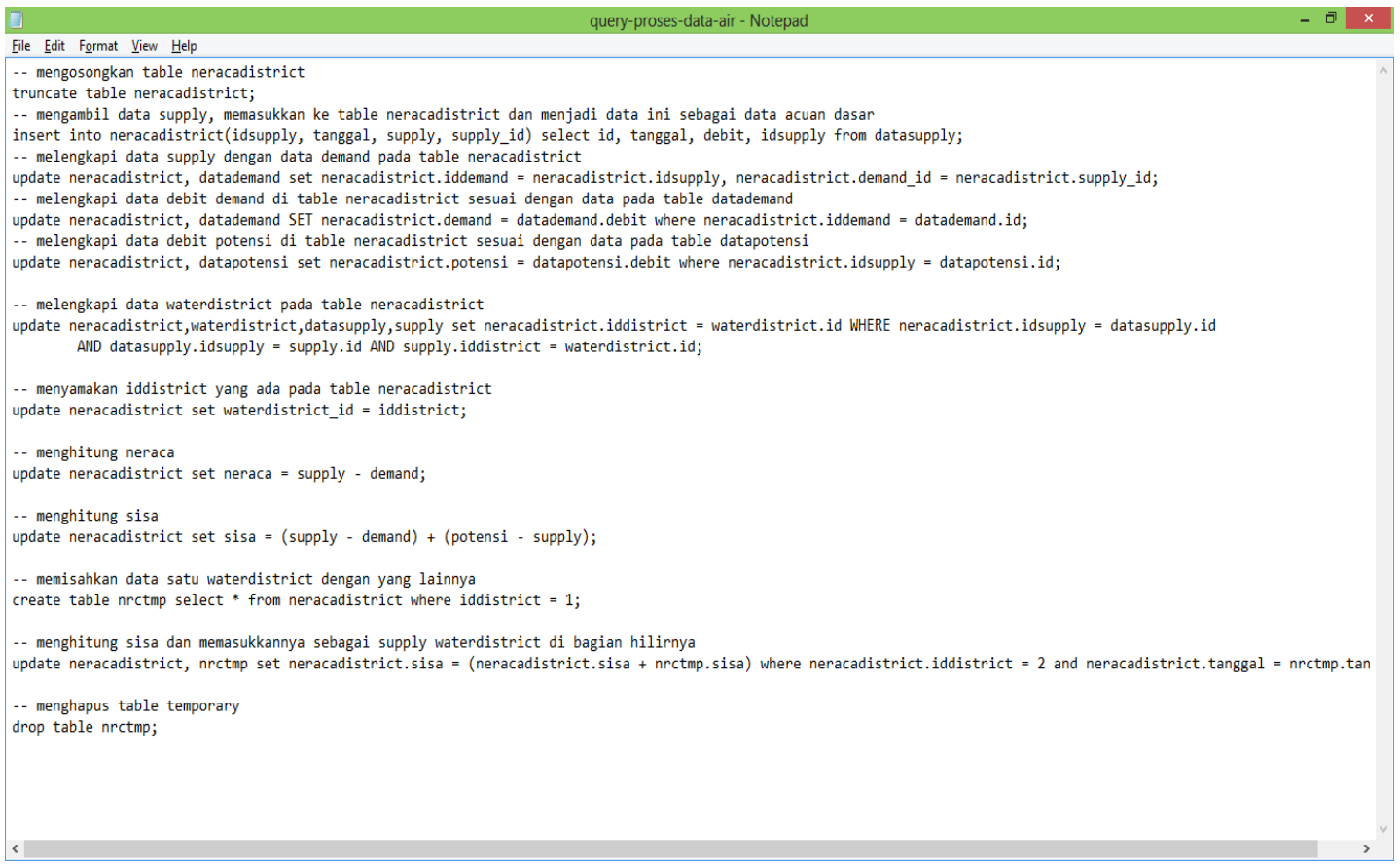

Gambar 6. Perintah query untuk perhitungan neraca air

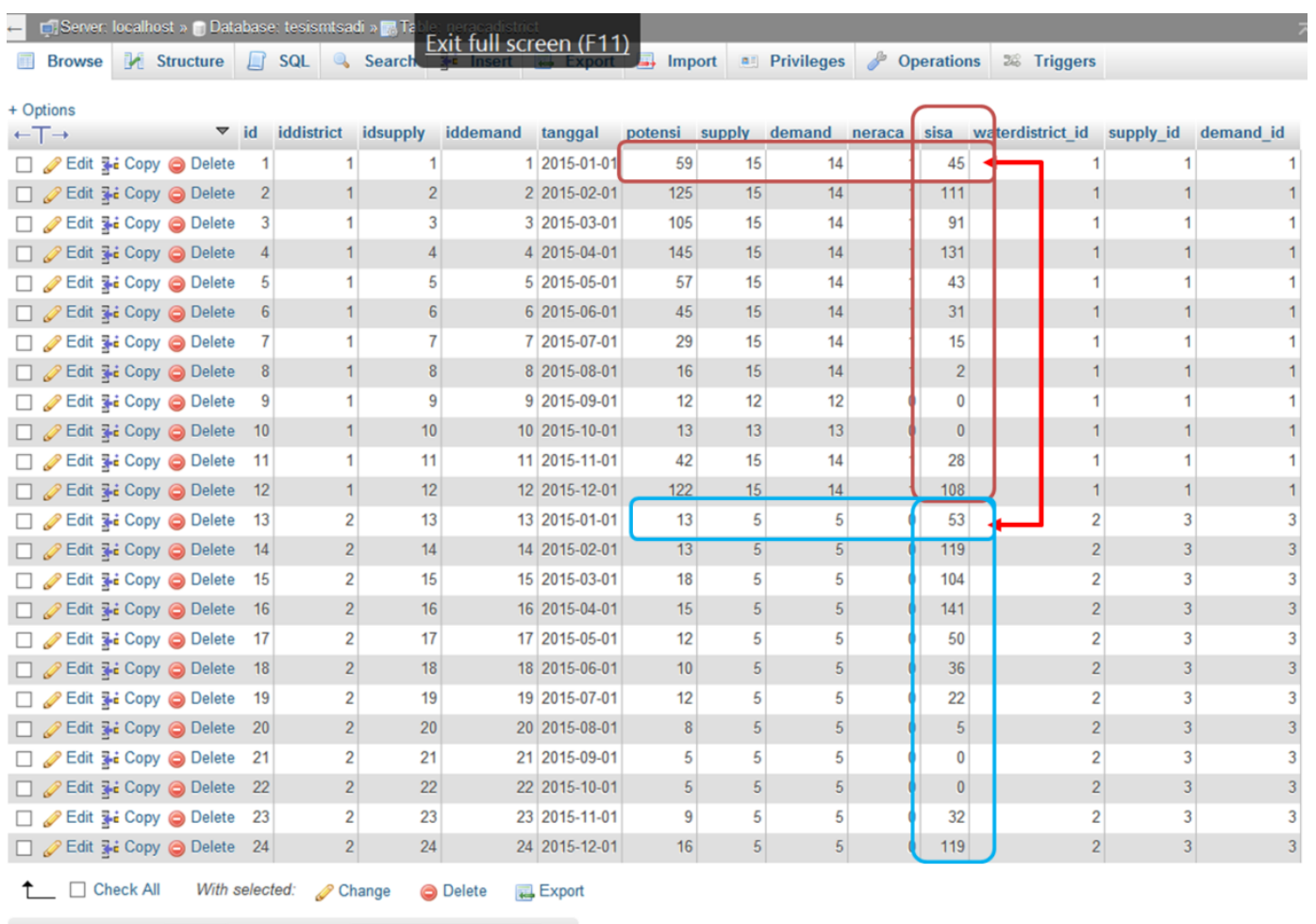

Gambar 7. Hasil hitungan query untuk imbangan air

\subsubsection{Data Berbasis Obyek}

Agar bisa diintegrasikan dengan peta atau skema yang memiliki referensi geografis maka tabel-tabel tersebut di atas harus dapat dikoneksikan dengan node, line atau polygon yang ada di peta atau skema. Oleh karena itu diperlukan satu langkah lagi yaitu dengan 
membuat satu field dalam data atribut yang ada di peta untuk field ID tabel. Sehingga setiap record yang ada dalam tabel akan sama persis datanya dengan tabel atribut yang ada di peta. Dengan demikian kalau dilakukan input atau perhitungan maka keduanya akan saling terhubung. Input data dapat dilakukan dari tabel atribut maupun tabel yang ada di basis data. Gambaran penambahan field pada tabel atribut di peta dapat dilihat pada Gambar 8.

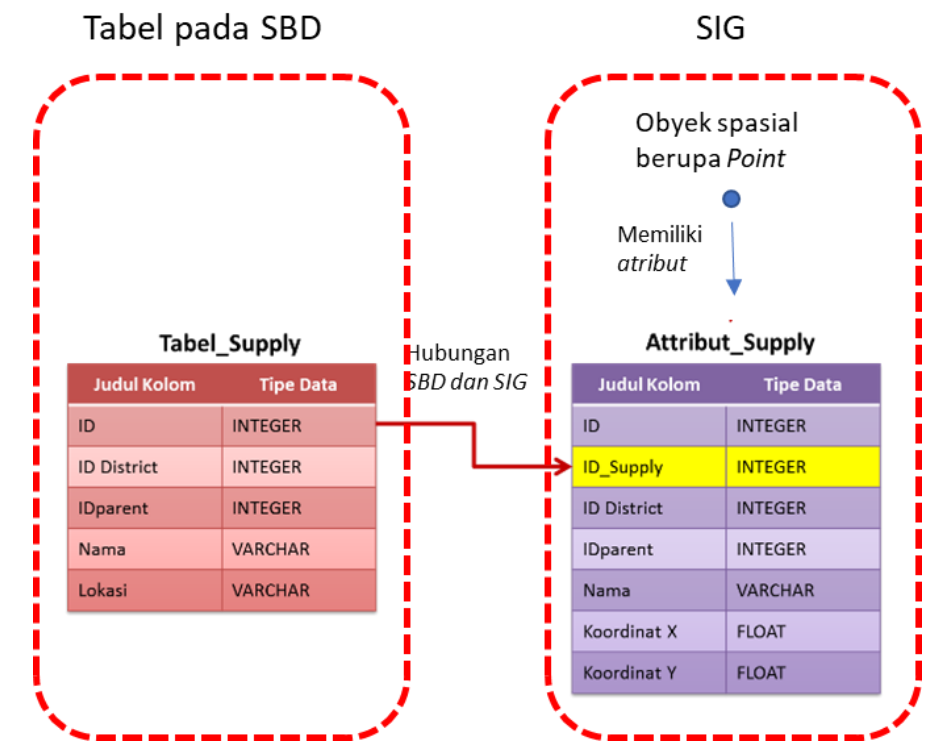

Gambar 8. Hubungan tabel basis data dengan tabel atribut pada peta

\subsection{Komparasi Model}

Model alokasi Ribasim merupakan sebuah aplikasi analisis alokasi air yang komprehensif dan terpadu. Di samping itu model ini mempunyai prinsip berkelanjutan (sustainable) karena memang digunakan untuk menganalisis perencanaan alokasi air untuk beberapa periode di masa yang akan datang. Berikut ini adalah komparasi antara model basis data hasil penelitian dengan Ribasim.

Tabel 1. Komparasi antara model basis data hasil penelitian dengan Ribasim

\begin{tabular}{ll}
\hline SISTEM BASIS DATA HASIL PENELITIAN & RIBASIM \\
\hline Sudah berorientasi obyek & Sudah berorientasi obyek \\
Sudah mempertimbangkan lokasi & Sudah mempertimbangkan lokasi \\
Belum menggunakan atribut peta & Belum menggunakan atribut peta \\
Pengembangan model fleksibel & Pengembangan model tergantung vendor \\
Input data manual atau import dari spreadsheet (misal excel) & Input manual kecuali data hidrologi \\
\hline
\end{tabular}

\section{KESIMPULAN}

1) Perhitungan alokasi air harus memperhatikan aspek ruang, waktu, kuantitas, dan kualitas.

2) Normalisasi data dan menyusunnya dalam tabel-tabel tersendiri agar tidak terjadi duplikasi data merupakan tahapan yang penting dalam penyusunan sebuah model basis data.

3) Model sistem basis data alokasi air sangat tergantung dari Entity Relationship Diagram (ER Diagram), karena hubungan antara satu tabel dengan tabel yang lain akan berpengaruh terhadap berjalannya sistem.

4) Model sistem basis data yang digunakan adalah parent-child structure, karena mampu membangun sistem alokasi secara berantai, maksudnya hasil satu water district (daerah layanan air) dapat menjadi input bagi water district di bagian hilirnya.

5) Penelitian ini sudah bisa membangun sebuah model sistem basis data untuk perencanaan alokasi air dengan mempertimbangkan aspek ruang dan waktu.

6) Adapun kekurangan atau keterbatasan dari sistem basis data ini adalah masih belum menggunakan atribut peta dan input data masih manual atau import dari spreadsheet. 
Vol. 22, No. 2, Oktober 2020

\section{UCAPAN TERIMA KASIH}

Ir. Tri Budi Utama, MT. atas saran dan arahannya dalam pengelolaan sumber daya air.

\section{DAFTAR PUSTAKA}

[1] B. Triatmodjo, Hidrologi Terapan. Yogyakarta: Beta Offset, 2008.

[2] D. Setiyadi, Sistem Basis Data. Bekasi: Teknik Informatika STMIK, 2010.

[3] E. Sutanta, Sistem Basis Data. Yogyakarta: Andi Offset, 1996.

[4] N. Guth and P. Klingel, Demand Allocation in Water Distribution Network Modelling - A GIS-Based Approach Using Voronoi Diagrams with Constraints, in Application of Geographic Information Systems, vol. 32, InTech, 2012, pp. 283 301.

[5] T.-H. Wen, M.-D. Su, and Y.-L. Yeh, A GIS-based framework of regional irrigation water demand assessment, Paddy Water Environ., vol. 2, no. 1, 2004, pp. 33-39.

[6] Q. W. Martin, Application of a GIS-based water allocation planning model to central Texas, WRPMD 1999 Prep. 21 st Century, 1999, pp. 1-6.

[7] Delf Hydraulics, Manual Software River Basin Simulation Model (Ribasim). 2001.

[8] H. Kristanto, Konsep dan Perencanaan Database. Yogyakarta: Andy Offset.

[9] N. C. Kresnanto, Konsep Sistem Informasi Geografis (SIG), 2018. [Online]. Available: https://www.researchgate.net/publication/322749577_Konsep_Sistem_Informasi_Geografis_SIG. [Accessed: 10-Mar2021].

[10] N. C. Kresnanto, Basis Data Spasial Sistem Jaringan Transportasi Jalan untuk Analisis dan Perencanaan Transportasi, no. June 2010, 2010. 